\section{An unusual and unpleasant experience with ERCP: nasal septum damage}

Endoscopic retrograde cholangiopancreatography (ERCP) has evolved into a largely therapeutic procedure for the management of a variety of benign and malignant pancreaticobiliary disorders. Although the most commonly related adverse events include pancreatitis, bleeding, perforation, cholangitis, and cardiopulmonary issues [1-3], a range of rare and often underappreciated complications can occur. Here we report on a case of nasal septum damage caused by an endoscopic nasobiliary drain (ENBD).

A 77-year-old man presented to our gastroenterology department with complaints of jaundice, itching, and weight loss during the previous 3 months. Medical history was unremarkable. Results of physical examination were insignificant except for jaundice. Laboratory parameters showed increased levels of alanine aminotransferase of $271 \mathrm{U} / \mathrm{L}$ (reference range 10-49), aspartate aminotransferase $370 \mathrm{U} / \mathrm{L}(0-34)$, alkaline phosphatase 473U/L (40-150), gamma-glutamyl transpeptidase $752 \mathrm{U} / \mathrm{L}(0-38)$, direct bilirubin $24 \mathrm{mg} / \mathrm{dL}(0-0.5)$, and total bilirubin $32.8 \mathrm{mg} / \mathrm{dL}(0.2-1.2)$.

Ultrasonography revealed dilated intrahepatic bile ducts and a normal common duct. Magnetic resonance cholangiopancreatography and contrast-enhanced computed tomography scan suggested a Bismuth-Corlette type II Klatskin tumor obstructing the common hepatic duct without major vascular involvement. Surgery was planned. However, as the patient's bilirubin levels were too high for surgery, a 7 Fr ENBD was placed via ERCP to achieve a rapid decrease in these levels. After 16 days, the patient showed damage to the membranous part of the nasal septum, where the catheter had been firmly

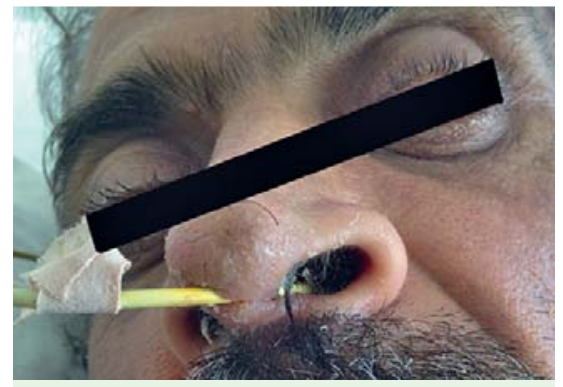

Fig. 1 Damage to the membranous nasal septum caused by a drainage catheter secured too tightly.

secured to the nasobiliary drain; the area had been hidden by a plaster at its exit from the nostril ( Fig. 1). The catheter was subsequently pulled out of position and withdrawn completely, and the lesion soon recovered.

Nasobiliary drainage catheters help the endoscopist by decompressing the biliary system, and provide effective and rapid treatment for obstructive jaundice, cholangitis, or management of postoperative bile leaks [4]. The nasobiliary tube is a continuous catheter that is placed after an ERCP using the Seldinger technique with a wire-guided system. The nasobiliary drain is secured to the nose after ERCP to keep it in place and this is commonly carried out by senior endoscopy nurses in our clinics, with attentive care and gentle hand motions. However, an ENBD catheter that is secured too tightly may cause nasal septum damage, as in our case, by impairing microvascular circulation, leading to local tissue necrosis. A nose complication caused by an ENBD at the exit of the nostril is extremely rare and may be overlooked. As a consequence, as well as showing the importance of nursing care following ERCP, this case indicates that endoscopists should pay attention not only to the pancreaticobiliary region but also to different areas where other complications may occur.

Endoscopy_UCTN_Code_CPL_1AK_2AI

Competing interests: None

\section{Serkan Torun ${ }^{1}$, Ufuk Barıș Kuzu², Bülent Ödemiş ${ }^{2}$}

${ }^{1}$ Department of Gastroenterology, Bartın State Hospital, Bartın, Turkey

2 Department of Gastroenterology, Turkiye Yuksek Ihtisas Education and Research Hospital, Bartın, Turkey

\section{References}

1 Freeman ML, Nelson DB, Sherman $S$ et al. Complications of endoscopic biliary sphincterotomy. N Engl J Med 1996; 335: 909-918

2 Andriulli A, Loperfido S, Napolitano G et al. Incidence rates of post-ERCP complications: a systematic survey of prospective studies. Am J Gastroenterol 2007; 102: 1781 - 1788

3 Cotton PB, Eisen GM, Aabakken L et al. A lexicon for endoscopic adverse events: report of an ASGE workshop. Gastrointest Endosc 2010; 71: 446-454

4 Sharma BC, Kumar R, Agarwal $N$ et al. Endoscopic biliary drainage by nasobiliary drain or by stent placement in patients with acute cholangitis. Endoscopy 2005; 37: 439-443

\section{Bibliography}

DOI http://dx.doi.org/

10.1055/s-0042-118454

Endoscopy 2016; 48: E348

(c) Georg Thieme Verlag KC

Stuttgart · New York

ISSN 0013-726X

\section{Corresponding author}

\section{Serkan Torun, MD}

Department of Gastroenterology

Bartın State Hospital, Bartın

Turkey 74100

Fax: +90-378-2271648

serkantorundr@gmail.com 